Natural Hazards and Earth System Sciences (2003) 3: 725-732

(C) European Geosciences Union 2003

Natural Hazards and Earth System Sciences

\title{
A model for the estimation of storm losses and the identification of severe winter storms in Germany
}

\author{
M. Klawa and U. Ulbrich \\ Institute of Geophysics and Meteorology, University of Cologne, Kerpener Str. 13, 50923 Köln, Germany
}

Received: 26 November 2002 - Revised: 1 April 2003 - Accepted: 3 June 2003

\begin{abstract}
A storm loss model for Germany is presented. Input data to the model are the daily maximum gust wind speeds measured at stations distributed over the country. The individual daily peak gust values are scaled with the local climatological upper $2 \%$ quantile at each station. This scaling serves to take local conditions at the stations into account, and thus permits a simple spatial interpolation of the storm field. The next step is the computation of a loss index for each storm. It is based on the excess of (scaled) wind speed over the upper $2 \%$ quantile, and on population numbers in the individual districts within Germany, with the latter serving as a proxy for the spatial distribution of values that could be affected by a storm. Using wind speeds in excess of the percentile value also serves to take spatial heterogeneity of vulnerability against storms into account. The aggregated storm index gives an estimate of the severity of an individual storm.

Finally, the relation between actual loss produced by a storm and the index is estimated using published annual insurance loss due to windstorm in Germany. Index values are accumulated for each year, and the relation to actual loss is computed. The average ratio for the whole reference period is eventually used. It is shown that the interannual variability of storm-related losses can be reproduced with a correlation coefficient of $r=0.96$, and even individual storm damages can be estimated. Based on these evaluations we found that only 50 storms account for about $80 \%$ of insured storm losses between 1970 and 1997.
\end{abstract}

\section{Introduction}

Severe winter storms belong to the most destructive natural hazards in Europe. Between 1970 and 1999 their share of natural hazard induced losses was more than $50 \%$ of the economic and even $60 \%$ of the insured losses in Germany (Mu-

Correspondence to: U. Ulbrich

(ulbrich@meteo.uni-koeln.de) nich Re, 1999, 2001). During the winters 1990 and 1999 storm damages reached record levels in Europe with more than 10 billion EUR paid by insurance companies. The economic losses were about twice as high (Munich Re, 1993, 2000; Swiss Re, 1993, 2000). The socio-economic importance of storms over Europe is thus evident. Nevertheless, it is felt that there are still deficits with respect to research on storms (Munich Re, 2001). Publications on the subject mainly focus on the meteorological development of individual events (e.g. McCallum, 1990; Ulbrich et al., 2001; Wernli et al., 2002) and on consideration of storm climatologies (e.g. Schiesser et al., 1997; Dreveton et al., 1998; WASA group, 1998), while few of the publicly available studies have an interdisciplinary approach, combining meteorological and socio-economic aspects of storms (some references are given in Sect. 4). This may be partly due to a lack of available loss data which are required for estimating the severity of the events' impacts. The present paper provides a simple approach for the estimation of the severity of storms on the basis of publicly available data.

\section{Basic considerations}

We focus on windstorms of major relevance for the insurance industry. Large losses are usually produced in storm events affecting large areas. Thus, the occurrence of small scale events like gusts produced by local thunderstorms (Kasperski, 2002), or tornadoes (e.g. Dotzek et al., 2000; Elsom et al., 2001) may be disregarded in this context.

The identification of the storm events are based on records from synoptic weather stations, as under the assumption of an ongoing availability of these data it will be possible to apply our model for future storms. A problem arising from the use of station data is that each station has its particular wind climate. High wind speeds frequently occur in an exposed area (e.g. hill tops), but are usually not causing any loss, while the same wind speeds may produce large loss in other areas. Such differences in regional wind speed can be 


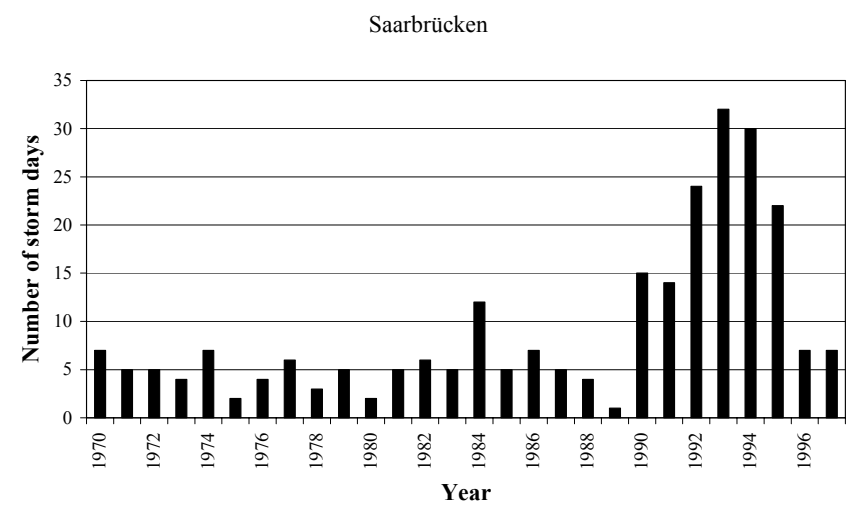

Fig. 1. Number of days with gust speeds above $20 \mathrm{~m} / \mathrm{s}$ at Saarbrücken. The inhomogeneity in 1989 is caused by a change of station location. The station was thus not used for the loss model.

estimated using numerical simulations (e.g. Goyette et al., 2001). As we do not intend to make use of numerical storm simulations we have to solve the problem that anemometerlevel winds from individual stations are not representative of large areas. The solution proposed here is a normalisation of winds with a local climatological extreme wind speed. This procedure is expected to remove the effect of differences in wind climate and permit a spatial interpolation of normalised station wind speeds.

A computation of spatially accumulated losses from wind data and a storm-loss function would normally require knowledge of the spatial distribution of insured values, but such data were not available for our study. Instead we use a surrogate for these values. A feasible first guess is to assume that insured values are proportional to population numbers (see also Walz, 2001) which are generally available with sufficient spatial resolution. So this problem is reduced to the estimation of the relation between insured values and population numbers. With respect to storm losses, this factor may be estimated from the accumulated annual loss data provided by the German insurance industry (Gesamtverband der Deutschen Versicherer e.V.) and a loss index produced by our storm loss model. This loss model is described in Sect. 4 following a description of the data used. A validation of the results (Sect. 5) will be based on the yearly loss data mentioned, and on loss data for single storm events. A discussion of results, conclusion and outlook are found in Sects. 6 and 7.

\section{Data}

\subsection{Gust wind speeds}

The German Weather Service (Deutscher Wetterdienst, DWD) provided data of maximum daily gust wind speeds (average velocity over two seconds) for about 90 different German stations between 1970 and 1997 . We carefully checked this data with respect to homogeneity as changes in instruments, relocating of stations and changing surface

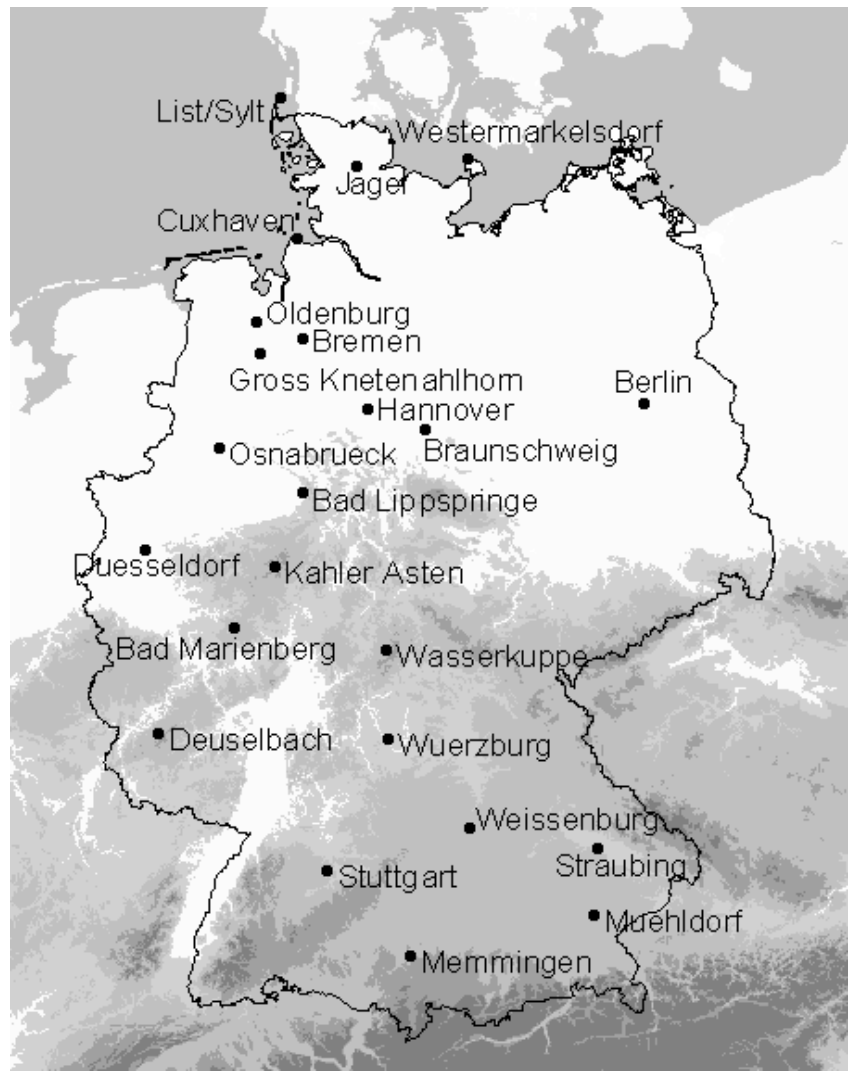

Fig. 2. Distribution of the stations used for the loss model. All stations shown are maintained by the German Weather Service (DWD).

roughness in the adjacent areas might influence the measured wind speeds. Most available time series were affected by such changes and had to be discarded as such inhomogenities caused abrupt leaps and artificial trends in the time series (see Fig. 1 for an example). We only kept 24 stations which showed only minor inhomogeneities. Their spatial distributions turned out to be quite homogeneous for western Germany (Fig. 2).

A problem also exists with respect to data coverage for the eastern parts of Germany. We had no data for the time period before the German reunification (1990), except what was available for Berlin-Tegel (1972-1997) and BerlinTempelhof (1970-1972). As we wanted to keep the data base constant with time, we used the other east German stations just for validation, but not for our final results.

\subsection{Insurance data}

The Gesamtverband der Deutschen Versicherer e.V. (German Insurance Association, subsequently abbreviated as GDV) provided yearly sums of insured losses (1980-1997, the years 1981 and 1987 are missing). These data contain information on storm losses in the following lines of business: 'residential buildings' (Verbundene Wohngebäude Versicherung, VWG), 'residential contents' (Verbundene 
Hausratversicherung, VHV) and 'commercial' (Allgemeine Sturmbedingungen, ASTB). Although they should enclose only storm related risks, these annual aggregated losses may include indirect storm losses associated with hail and rain. This source for losses can, however, generally be neglected against the direct storm losses (personal communication to several reinsurance and primary insurance companies). Note that this is not true in other lines of insurance business like motor insurance, where hail, for example, is a major factor.

Aggregated losses of selected storms published by the Munich $\operatorname{Re}(1993,1999)$ will be used for the validation of our model. It should be noted that these numbers are based on the market insight of Munich Re and so the given amounts may not always be representative for the whole insurance market. Some of the storm loss estimates published by $\mathrm{Mu}$ nich Re have been updated in the meantime (personal communication with Munich Re). A further aspect which must be taken into account when comparing loss estimates for individual storms published by insurance companies and estimated from meteorological data is the definition of a single storm event. In some treaties between primary insurance and reinsurance companies storm losses are assigned to one event if they happen within a $72 \mathrm{~h}$ period. Thus two or more events within a storm series which would be distinguished from a meteorological point of view may be counted as one event by an insurance company. This might be applicable to the storms 'Vivian' and 'Wiebke' over Germany 26 and 28 February 1990 or 'Lothar' and 'Martin' over France 26 and 28 December 1999.

Loss data from different years are affected by inflation as well as by changes in the number and the specifications of the insurance policies. Additional effects may be caused by an improvement of building standards (e.g. fixed tiles), which may reduce loss at a given storm wind speed. In order to account for these inhomogeneities we detrended all loss data by assuming a total increase of insured values by $5 \%$ per year. This value is somewhat larger than the average inflation rate for buildings in Germany between 1980 and 1995 (about 3.5\% according to the German federal office for statistics, http://www.destatis.de/indicators/d/d_bprumr.htm), but smaller than the respective estimates published by Munich $\operatorname{Re}(2001,2002)$ for Europe. The Munich Re estimates that the insured values in Europe increased by a factor of 1.8-2 within the years 1990-1999, which is equivalent to a rate of about 7-8\% per year (Munich Re, 2002).

We have chosen 1990 as our reference year for which detrended insured losses are computed. Motivations for this choice are the fact that 1990 is approximately in the middle of the available insurance data so that correction factors remain small, and that there is no need to correct the data for the storm series that occurred during this year.

The population density distribution used as an estimate for the spatial distribution of insured values is obtained from a commercial Geographical Information System (ArcView, ESRI). Data are resolved on the scale of districts within Germany.

\section{Design of the storm loss model}

\subsection{Choice of storm loss function}

Several definitions of storm loss functions have been developed from loss evaluations. A function based on an exponential approach (loss $\left.\sim \exp \left(v_{\max }\right)\right)$ was suggested by Dorland et al. (1999). This function was calibrated to data of storm damages to roofs and households in the Netherlands. However, only five very intense storm events were considered, and thus the result may not be representative in a climatological sense.

A few systematic evaluations of storm losses in Germany were published by reinsurance companies following the storm series in the winter of 1989/1990 (e.g. 'Daria', 25 January, 'Wiebke', 28 February 1990). Munich Re (1993) found out that the loss extent of storms increases with almost the cube of the maximum gust wind speeds $\left(v_{\max }^{2.7} \sim \operatorname{loss}\right)$. ' $v^{3}$ relations' were also used in other storm loss studies (Palutikof and Skellern, 1991; Angermann, 1993; Lamb, 1991). Loss evaluations performed by Munich Re after the storm series of December 1999 generally confirmed the earlier results, but suggested higher exponents $\left(v^{4}\right.$ to $\left.v^{5}\right)$ in the storm loss function in order to meet the losses in areas with extreme gusts (Munich Re, 2002).

From a physical point of view the cube of wind speed is proportional to the advection of kinetic energy. Businger and Businger (2001) also note that the magnitude of the viscous dissipation of turbulent kinetic energy in the surface layer of storms is a cubic function of wind speed. Nevertheless, it is mainly empirical evidence which supports the $v^{3}$-relationship of wind speeds and economic loss generally used in such investigations (e.g. Munich Re, 1993; Palutikof and Skellern, 1991; Lamb, 1991).

For our storm model we have chosen to use a relation between loss and maximum wind speeds which is based on the cubic relationship, but takes into account that damages are only produced when wind speeds exceed a certain threshold, and that they grow with wind speeds in excess of this threshold.

Insurance companies in Germany usually pay for storm losses if gust wind speeds above $20 \mathrm{~m} / \mathrm{s}$ have been measured at a neighbouring weather station during a storm. The level of $20 \mathrm{~m} / \mathrm{s}$ approximately coincides with the $98 \%$-percentile value (= upper $2 \%$ quantile of the distribution) of the daily maximum gust wind speed at German flatland stations (Table 1). There are more days with maximum wind speeds above $20 \mathrm{~m} / \mathrm{s}$ in exposed areas such as mountain tops or at the coastline. In List (island of Sylt), for example, winds of this magnitude occur in about $20 \%$ of all days in a year - in most cases without damage worth mentioning. Apparently both buildings and nature (e.g. forests) are adapted to these conditions. Such an adaptation is also enforced by building regulations which take wind speeds at fixed return periods into account (Böllmann and Jurksch, 1984; Chandler et al., 2001). Thus we decided to use the local $98 \%$ percentile value of daily maximum gust wind speed at a station as the min- 
Table 1. Percentile values of daily maximum gust wind speed for different German weather stations, the absolute maximum, and relative values during the period 1970-1997

\begin{tabular}{|c|c|c|c|c|c|c|c|c|}
\hline \multirow{2}{*}{$\begin{array}{l}\text { Station } \\
\text { Weissenburg }\end{array}$} & \multicolumn{2}{|c|}{ Lon/Lat } & \multirow{2}{*}{$\frac{V_{99} / V_{98}}{1.1}$} & \multirow{2}{*}{$\frac{V_{99.5} / V_{98}}{1.2}$} & \multirow{2}{*}{$\frac{V_{\max } / V_{98}}{1.62}$} & \multirow{2}{*}{$\begin{array}{l}V_{\max } \\
32.5\end{array}$} & \multirow{2}{*}{$\begin{array}{l}V_{98} \\
20\end{array}$} & \multirow{2}{*}{$\begin{array}{c}\text { Type } \\
\text { Flatland }\end{array}$} \\
\hline & $49.01^{\circ} \mathrm{N}$ & $10.58^{\circ} \mathrm{E}$ & & & & & & \\
\hline Düsseldorf & $51.1^{\circ} \mathrm{N}$ & $6.46^{\circ} \mathrm{E}$ & 1.11 & 1.22 & 1.73 & 38 & 21.8 & Flatland \\
\hline Berlin & $52.28^{\circ} \mathrm{N}$ & $13.24^{\circ} \mathrm{E}$ & 1.09 & 1.18 & 1.76 & 39 & 22.2 & Flatland \\
\hline Stuttgart & $48.41^{\circ} \mathrm{N}$ & $9.13^{\circ} \mathrm{E}$ & 1.1 & 1.22 & 1.95 & $39.9^{*}$ & 19.9 & Hilly \\
\hline Braunschweig & $52.18^{\circ} \mathrm{N}$ & $10.27^{\circ} \mathrm{E}$ & 1.11 & 1.21 & 1.86 & 40 & 21.6 & Flatland \\
\hline Kahler Asten & $51.11^{\circ} \mathrm{N}$ & $8.29^{\circ} \mathrm{E}$ & 1.07 & 1.17 & 1.73 & 48 & 27.6 & Mountain \\
\hline Cuxhaven & $53.52^{\circ} \mathrm{N}$ & $8.42^{\circ} \mathrm{E}$ & 1.09 & 1.19 & 1.68 & 45 & 26.8 & Coast \\
\hline Sylt & $55.01^{\circ} \mathrm{N}$ & $8.25^{\circ} \mathrm{E}$ & 1.08 & 1.19 & 1.77 & $53.3^{* *}$ & 29.9 & Coast \\
\hline
\end{tabular}

The following abbreviations are used:

$V_{98}=98 \%$-quantile of the daily maximum gust wind

$V_{99}=98 \%$-quantile of the daily maximum gust wind

$V_{99.5}=99.5 \%$-quantile of the daily maximum gust wind

$V_{\max }=$ max. gust wind speed measured between 1970-1997,

* value of 26 December 1999, measured during the storm 'Lothar'

** value of 3 December 1999, measured during the storm 'Anatol'

imum wind speed expected to produce any loss. This is in line with the argument used by Palutikof and Skellern (1991) for their definition of storm vulnerability areas which they based on return periods of wind extremes at British weather stations. It implies that at any location (irrespective of the environmental characteristics) storm damages are assumed to occur at $2 \%$ of all days.

The 'adaptation' to wind climate can also be expected to affect the degree of damage increases with growing wind speed in excess over the threshold value: The same absolute excess wind speed will lead to less/more damage when the threshold value is high/low. Thus we decided to use gust winds normalised with the local threshold value as the relevant factor for wind damage rather than absolute gusts.

Loss at a station is assumed to grow with the cube of normalised gust intensity in excess of the $98 \%$ percentile threshold as given in the following equation:

$\operatorname{loss} \propto\left(\frac{v_{\max }}{v_{98}}-1\right)^{3} \quad$ for $\quad v_{\max }>v_{98}$

with

$v_{\max }=$ maximum wind speed for the day considered

$v_{98}=98 \%$ quantile of maximum wind speeds during

the reference period

Note that the use of the cube of the excess over the threshold wind speed in Eq. (1) also implies that a small absolute increase of $v_{\max }$ above the threshold will have a strong effect on loss. In this respect our approach differs from cubic storm loss functions which use absolute rather than excess wind speeds. This is relevant when comparing our approach to storm loss functions employed in work referenced previously in this section.

\subsection{Use of parameters other than wind}

It has been suggested that further parameters, in addition to wind speed, should be included into a storm loss function. Swiss Re (1993) discusses the influence of storm duration and accompanying precipitation on the loss. They presented some evidence for a positive correlation between losses and storm duration and they remarked that accompanying precipitation might increase losses in single cases.

While it is possible to define storm duration objectively (MacClenahan et al., 2001) it is not easy to obtain a reliable estimation of its effect on the loss sum generated by a storm. The same is true for the impact of precipitation, in particular as precipitation and storm intensities are physically connected: Latent heat release is a major source for energy of intense storm events (Wernli et al., 2002), and by changing the vertical static stability it may also influence the gustiness of a storm (Brasseur, 2001). There is a risk of an 'over-fitting' of functions when too many parameters are used in such an empirical relation. Dorland et al. (1999) mention similar arguments for restricting the parameters in their storm-loss relation to three parameters. We will thus not include precipitation or storm duration into the present version of our model.

\subsection{Spatial interpolation and aggregation of a loss index}

The ratios between several percentile values of extreme winds at German stations in differently exposed areas are similar (Table 1). As a consequence, gust wind speeds which are scaled by the local percentile value $v_{98}$ should provide a measure of storm intensity which is largely independent of local conditions at a particular station. It is thus possible to perform a spatial interpolation of the normalised gust data from the available weather stations, and thus to compute a "footprint" of a storm. Examples of such footprints 


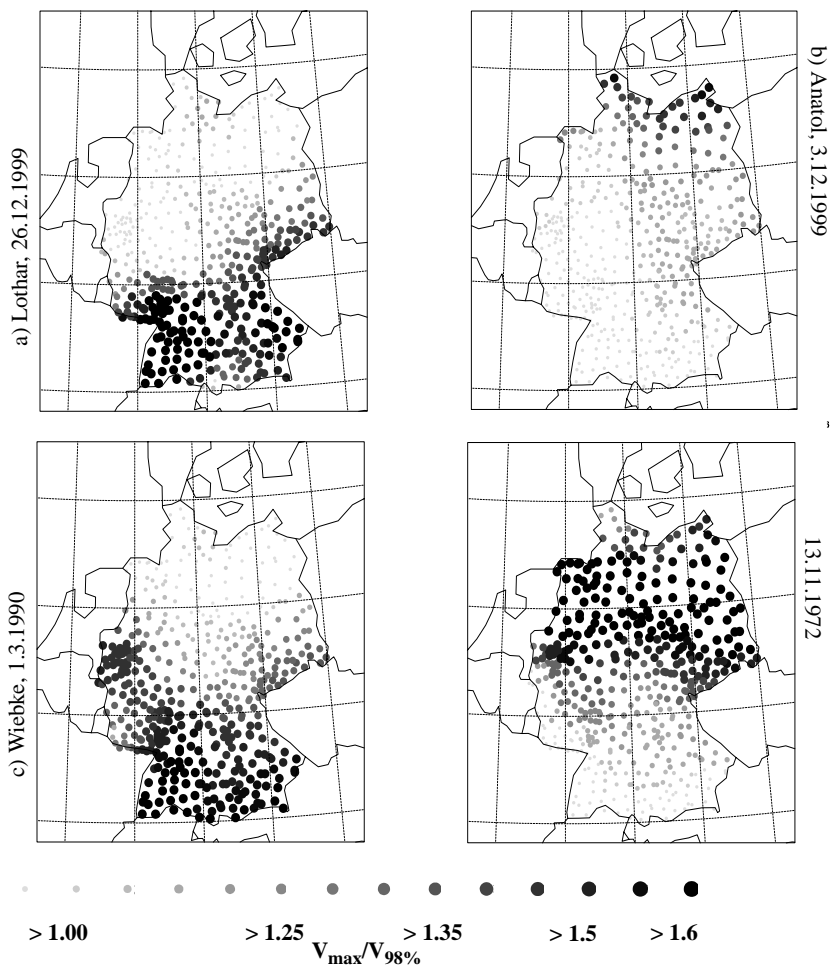

Fig. 3. Scaled maximum gust wind speeds (see text) for 4 intensive storm events in Germany. The maximum gust wind speeds are measured during a $24 \mathrm{~h}$ period. Dots indicate gust intensities which have been interpolated and assigned to districts within Germany.

(which are based on wind data measured within a 24-h period) using the weather stations selected (Fig. 2) are shown in Fig. 3. Details of the wind field related to orography or surface roughness (as output from a mesoscale model, e.g. Kalthoff et al., 2003; Goyette et al., 2001) are not visible in Fig. 3, but effects of the heterogeneous surface on actual wind speeds could be estimated by multiplication of the normalized values with local values of $v_{98}$.

After the generation of a 'footprint' of a storm, the loss index is computed over all districts within Germany by multiplying the number of inhabitants of each district with the cube of the ratio of $\left(V_{\max }-V_{98}\right) / V_{98}$ (see Eq. 1) for the area. Aggregating the index values over all districts we obtain a loss index value "LOSSINDEX" for Germany for a 24-h period which is proportional to the actual loss. It will approximately include the effect of the spatial distribution of values, but the factor between LOSSINDEX and the actual loss must still be determined.

\subsection{Estimation of absolute loss}

The LOSSINDEX values computed for individual 24-h periods are added for each individual year. The time series of these annual values should correspond to the time series of detrended annual loss data provided by the 'GDV' (see Sect. 3). The regression coefficient $c$ between these time se-

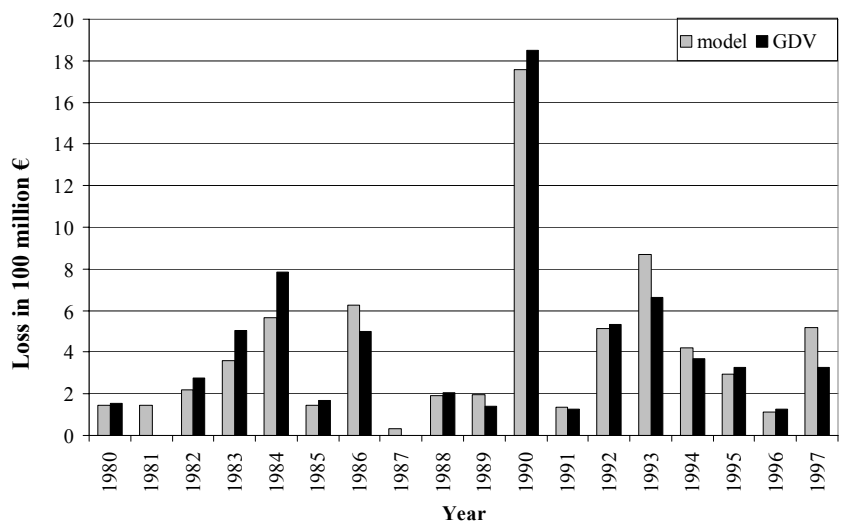

Fig. 4. Insured annual accumulated losses in Germany. Comparison between detrended loss data (basic year $=1990$ ) reported by the German Insurance Association (GDV), and loss estimations by the loss model. The changes due to the re-unification of Germany have been taken into account in both time series.

ries is the factor between the annual loss index and actual annual loss. It should also be applicable for computing actual loss from the index computed for an individual storm event using the equation:

$$
\begin{aligned}
\text { loss } & =c^{*} \text { LOSSINDEX } \\
& =c^{*} \sum_{\text {districts }} \text { pop }(\text { districts })\left(\frac{v_{\max (\text { district })}}{v_{98(\text { district })}}-1\right)^{3}
\end{aligned}
$$

where pop (district) is the population number given for an individual district.

\section{Validation}

In Fig. 4 the time series of annual insured storm losses in Germany (after removal of the trend) is compared to the output of our loss model. The model approximately reproduces the annual loss data for the time period considered. Both time series are highly correlated $(r=0.96)$, which demonstrates the general suitability of our model. A small long term trend can, however, be detected. At the beginning of the time series our estimation of losses is somewhat too small, while it is too high towards the end. This could suggest that our detrending of insurance data is too strong, and better agreement would be obtained by assuming a smaller trend than $5 \%$ per year. The subsequent validation for individual storm events suggests, however, that the use of a $5 \%$ rate is appropriate for estimations of the loss arising from the welldocumented events 'Lothar' and 'Anatol' at the end of 1999 (see below). A lower rate would result in an underestimation of these events by our model.

Table 2 gives a list of storm events. The loss estimations computed by our model are compared with those published by the Munich Re (1999). All losses are referenced to the year 1990. Loss estimates are given both for western Germany and for the re-unified Germany, as values published by 
Table 2. Simulated and observed storm losses for Germany in EURO (referenced to the year 1990). The original data published by Munich $\operatorname{Re}(1999,2002)$ are converted to values of the year 1990 assuming a linear trend of 5\%/year. Original data published by Munich Re are also given. Note that the losses according to Munich Re include only former West Germany before 1991. The value given for the storm Verena (marked with $\mathrm{a}^{*}$ ) was corrected from the initially published amount of 40 Million DM (Munich Re, 1999).

\begin{tabular}{lccccc}
\hline Storm & \multicolumn{2}{c}{$\begin{array}{c}\text { Simulated loss in 1990 values } \\
\text { unified Germany }\end{array}$} & $\begin{array}{c}\text { Loss according to } \\
\text { Munich Re in 1990 values }\end{array}$ & $\begin{array}{c}\text { Loss according } \\
\text { to Munich Re }\end{array}$ \\
\hline Niedersachsen-Orkan & 13.11 .1972 & 695 & 525 & 615 & 230 \\
Capella & 03.01 .1976 & 495 & 415 & 510 & 255 \\
Daria & 25.01 .1990 & 455 & 445 & 510 & 510 \\
Hertha & 03.02 .1990 & 280 & 260 & 255 & 255 \\
Judith & 08.02 .1990 & 125 & 75 & 25 & 25 \\
Vivian & 26.02 .1990 & 460 & 420 & 510 & 510 \\
Wiebke & 28.02 .1990 & 500 & 485 & 510 & 510 \\
Verena & 13.01 .1993 & 285 & - & 295 & $* 45$ \\
Lore & 27.01 .1994 & 250 & - & 65 & 240 \\
Anatol & 03.12 .1999 & 50 & - & 445 & 100 \\
Lothar & 26.12 .1999 & 505 & - & in US $\$$ ) \\
\hline
\end{tabular}

Munich Re do not include figures for the eastern parts of Germany before 1991. General agreement is found between the loss estimations of our model and the reference data from Munich Re. This suggests that our model is generally capable of giving a reasonable estimation of loss produced by individual storms, in spite of the simplifying assumptions made.

Table 2 also reveals a number of deviations between our estimates and the published loss data. We will now discuss these briefly, particularly mentioning aspects that are not related to the model. The major events of 1990 ('Daria', 'Vivian', 'Wiebke' and 'Judith') are part of a storm series that also included 3 more storms not listed in the table. The three most severe storms are underestimated by $5-20 \%$ by our approach while our estimate is much larger than the insurance values with respect to 'Judith' (8 February 1990). It cannot be ruled out that part of these differences are associated with the primary insurers' assignment of loss to the individual events within the series (personal communication to different (re)insurance companies). It appears that part of the loss assigned to the largest events by the insurance companies should rather be assigned to the smaller events. This would lead to a closer agreement of our estimates and the observed losses.

With respect to losses produced by the storm Judith, the comparatively low loss reported by Munich Re may have to be assigned to the fact that its footprint had a large overlap with that of Daria a few days earlier. As the first storm of such a series will affect most of the 'vulnerable' buildings, a second event will thus cause less new damage. With respect to 'Verena' (13 January 1993) the models' figures are clearly above the Munich Re's estimate. Given that total storm loss of 1993 reported by primary insurers to the GDV (1.58 billion DM, detrended: 1.3 billion DM $=665$ Million EUR, Fig. 3) are in rather good agreement with the sim-
Table 3. Storm loss classes, including all events individually producing loss of more than the given percentage of average annual storm loss between 1970 and 1997 in Germany (first column). Loss for each class is given in values of the year 2000. The last column gives an estimate of the percentage of total loss explained by the storms belonging to this class.

\begin{tabular}{rccc}
\hline $\begin{array}{c}\text { Storm loss class, } \\
\text { in percent of mean annual } \\
\text { storm loss in Germany } \\
\text { (loss in values of year 2000) }\end{array}$ & $\begin{array}{c}\text { Number of } \\
\text { events } \\
1970-1997\end{array}$ & $\begin{array}{c}\text { Percentage of } \\
\text { accumulated insured } \\
\text { storm loss } \\
\text { (VHV,VWV, ASTB) }\end{array}$ \\
\hline $5 \%$ & $(>30$ Mill. EUR) & 88 & $88.00 \%$ \\
$10 \%$ & $(>60$ Mill. EUR) & 50 & $80.00 \%$ \\
$20 \%$ & $(>120$ Mill. EUR $)$ & 28 & $68.00 \%$ \\
$50 \%$ & $(>300$ Mill. EUR $)$ & 15 & $53.00 \%$ \\
$100 \%$ & $(>600$ Mill. EUR) & 5 & $25.00 \%$ \\
\hline
\end{tabular}

ulated losses for this year (detrended: 870 Million EUR), we believe that the loss published by Munich Re (1999) is too small.

The published insured losses related to the storms 'Lothar' (26 December 1999) and 'Anatol' (3 December 1999) are reasonably well approximated by our model. 'Lothar' is overestimated by about $15 \%$ compared to the Munich Re values, whereas storm 'Anatol' is underestimated by $30 \%$. Note that this approximate agreement is obtained without application of a modified storm-loss function for the events in 1999 as was suggested by Munich Re (2002). They suggested that for 'Lothar' the exponents in the loss function should be raised to 4 to 5 . As mentioned earlier, the use of wind in excess of a threshold in our approach (Eq. 1) leads to a larger increase of damage with gust wind speed than would be computed for a cubic function without a threshold. 
One of the factors determining the reliability of the loss estimates produced by our model is the quality of the footprint generated from the station data. With respect to Lothar we found that our overestimation of loss (Table 3) could be reduced by including station measurements of south of Stuttgart, as this would result in a better representation of Lothar's rather narrow foot print (Wernli et al., 2002; Ulbrich et al., 2001). Preliminary tests produce a loss estimation reduced by $10 \%-15 \%$, thus leading to a closer agreement with values reported by Munich Re.

\section{Loss classes}

Using the storm events identified by our approach we can analyse the contribution of weak and strong events to total loss sums for the period 1970-1997. We sorted the events according to their loss. Table 3 distinguishes events that produce $5 \%, 10 \%, 20 \%, 50 \%$ and $100 \%$ of the average annual loss during this period, which is 600 Million EUR (in values of the year 2000 , detrended with $+5 \%$ per year from the year 1990). The number of events belonging to different loss classes are given in the second row.

The share of different loss classes in the total losses between 1970-1997 is given in the third row. It indicates that the five most expensive events caused $25 \%$ of all losses in this period. The next 45 events with a minimum of at least 100 Million EUR account for 55\% of all losses. The top 50 events are responsible for $80 \%$ of all storm losses (residential building, content and commercial storm losses) in Germany. It seems therefore to be justified that studies should focus on storms with a minimum loss of about 50 Million EUR (in value relative to the year 2000).

For future studies, we present the top 50 loss events with our loss approach in Table 4. Only one summer event (Nr. 37, 11-12 July 1984) can be found in the Table. On this day there was a major hailstorm in southern Germany that in particular struck the city of Munich. This storm is included in the table as high gust wind speeds were recorded at several German stations. However, most insured losses (about 700 Million EUR in 1984, Munich Re, 1999) were caused by hail rather than by gusts.

\section{Conclusion}

We have presented a model for the estimation of insured storm losses in Germany. The model results show that it is possible to obtain a rather good estimate of losses on the basis of gust speeds at weather stations and the spatial distribution of population as a proxy for insured value. As these data sets can easily be obtained, our model constitutes a simple but effective methodology for the identification of storm events relevant for insurance industry.

Our estimations suggest that extreme storm events such as 'Daria' or 'Cappela-Storm' (loss $>600$ Million EUR, Table 2) caused $25 \%$ of all insured storm loss in Germany between 1970 and 1997 (Table 3). This result stresses
Table 4. Ranking of the 50 most intensive storm events in Germany according to the loss model, and the respective loss in \% of estimated insured average annual loss in Germany

\begin{tabular}{|c|c|c|}
\hline Rank & Date & Loss in $\%$ \\
\hline 1 & 13 Nov. 1972 & 170 \\
\hline 2 & 28 Feb. 1990 & 120 \\
\hline 3 & 3 Jan. 1976 & 120 \\
\hline 4 & 26 Feb. 1990 & 110 \\
\hline 5 & 25 Jan. 1990 & 110 \\
\hline 6 & 23 Nov. 1984 & 90 \\
\hline 7 & 19 Jan. 1986 & 70 \\
\hline 8 & 13 Feb. 1990 & 70 \\
\hline 9 & 13 Jan. 1993 & 60 \\
\hline 10 & 3 Feb. 1990 & 60 \\
\hline 11 & 9 Dec. 1993 & 60 \\
\hline 12 & 28 Jan. 1994 & 50 \\
\hline 13 & 14 Jan. 1984 & 50 \\
\hline 14 & 13 Feb. 1997 & 50 \\
\hline 15 & 24 Jan. 1993 & 50 \\
\hline 16 & 25 Nov. 1992 & 40 \\
\hline 17 & 22 Jan. 1995 & 40 \\
\hline 18 & 20 Oct. 1986 & 30 \\
\hline 19 & 26 Jan. 1995 & 30 \\
\hline 20 & 8 Feb. 1990 & 30 \\
\hline 21 & 1 Feb. 1983 & 20 \\
\hline 22 & 24 March 1986 & 20 \\
\hline 23 & 18 Dec. 1986 & 20 \\
\hline 24 & 2 April 1973 & 20 \\
\hline 25 & 18 Jan. 1983 & 20 \\
\hline 26 & 28 March 1997 & 20 \\
\hline 27 & 3 Jan. 1984 & 20 \\
\hline 28 & 27 Nov. 1983 & 20 \\
\hline 29 & 16 March 1978 & 10 \\
\hline 30 & 4 Jan. 1983 & 10 \\
\hline 31 & 25 Feb. 1997 & 10 \\
\hline 32 & 21 March 1992 & 10 \\
\hline 33 & 19 Dec. 1974 & 10 \\
\hline 34 & 16 Jan. 1974 & 10 \\
\hline 35 & 1 March 1982 & 10 \\
\hline 36 & 12 Jan. 1993 & 10 \\
\hline 37 & 11 July 1984 & 10 \\
\hline 38 & 19 Feb. 1997 & 10 \\
\hline 39 & 19 April 1980 & 10 \\
\hline 40 & 9 Sept. 1997 & 10 \\
\hline 41 & 10 Dec. 1979 & 10 \\
\hline 42 & 13 March 1992 & 10 \\
\hline 43 & 15 Dec. 1982 & 10 \\
\hline 44 & 27 March 1972 & 10 \\
\hline 45 & 20 Dec. 1993 & 10 \\
\hline 46 & 30 Nov. 1976 & 10 \\
\hline 47 & 24 Dec. 1977 & 10 \\
\hline 48 & 4 Jan. 1981 & 10 \\
\hline 49 & 20 Jan. 1976 & 10 \\
\hline 50 & 21 Jan. 1976 & 10 \\
\hline
\end{tabular}

the importance of these extreme events, but we were also able to show that losses from smaller and more frequent 
events ( $>50$ Million EUR) accumulate to considerable loss amounts. These events are normally unnamed and attain little attention from the public.

We consider our model as a basis for future work. A more detailed validation of our approach is necessary and may lead to more insight with respect to this field of research. It would require, however, the availability of spatially and temporally resolved loss data, and data on the distribution and development in time of the values. Using such data one could, for example, check to see how far our assumption regarding the degree of adaptation to the regional wind climate for different regions are correct, or determine the amount of relative loss reduction for storm series as compared to single storm events.

Acknowledgements. We would like to acknowledge the provision of annual loss data by the German Insurance Association GDV, and of gust data by the German Weather Service DWD. The work was supported by the German Minister of Research under grant 01 LA 9861/5, and by the European Union within the projects STOEC (Storm Track - upper Ocean interaction and European Climate, grant ENV4-CT97-0499) and MICE (Modelling the Impacts of Climate Extremes, grant EVK2-CT-2001-00118. We would like to thank Drs. O. Burghoff, E. Faust, Y. Tatge, and in particular T. Grollmann for their advice with respect to the re-insurance aspects of this paper.

\section{References}

Angermann, A.: Sturmszenarien und Schadenhäufigkeit von Stürmen über Deutschland, Diploma thesis at the Institut für Geophysik und Meteorologie der Universität zu Köln, 104, 1993.

Barkhausen, M.: Untersuchung von Intensitäten und Auftrittswahrscheinlichkeiten außertropischer Stürme in Mittelund Westeuropa anhand historischer Sturmfelder (1967-1997), Diploma thesis at the Institut für Meteorologie der Universität München, 1997.

Böllmann, G. and Jurksch, G.: Ein Beitrag zur Festlegung der Grundwind- und Nennböengeschwindigkeit im Binnenland der Bundesrepublik Deutschland für die DIN-NORM 1055, Teil 4, Meteol. Rdsch., 37, 1-10, 1984.

Brasseur, O.: Development and application of a physical approach to estimating wind gusts, Mon. Wea. Rev., 129, 5-25, 2001.

Businger, S. and Businger, J. A.: Viscous dissipation of turbulence kinetic energy in storms, J. Atmos. Sci, 58, 3793-3796, 2001.

Chandler, A. M., Jones, E. J. W., and Patel, M. H.: Property loss estimation for wind and earthquake perils, Risk Analysis, 21 , 235-249, 2001.

Dorland, C., Tol, R. S. J., and Palutikof, J.: Vulnerability of the Netherlands and Northwest Europe to storm damage under climate change, Clim. Change, 43, 513-535, 1999.

Dotzek, N., Berz, G., Rauch, E., and Peterson, R. E.: The relevance of Johannes P. Letzmann's "Guidelines for Research on Tornadoes, Waterspouts and Dust Devils" for contemporary tornado research, Meteorol. Z., 9, 165-174, 2000.

Dreveton, C., Benech, B., and Jourdain, S.: Classification of windstorms over France, Int. J. Climatology, 18, 1325-1343, 1998.
Elsom, D. M., Meaden, G. T., Reynolds, D. J., Rowe, M. W., and Webb, J. D. C.: Advances in tornado and storm research in the United Kingdom and Europe: the role of the Tornado and Storm Research Organisation, Atmosph. Res., 56, 19-29, 2001.

Goyette, S., Beniston, M., Caya, D., Laprise, R., and Jungo, P.: Numerical investigation of an estreme storm with the Canadian Regional Climate Model: the case study of windstorm VIVIAN, Switzerland, February 27, 1990, Clim. Dyn, 18, 145-168, 2001.

Kalthoff, N., Bischoff-Gauß, I., and Fiedler, F.: Regional effects of large-scale extreme wind events over orographically structured terrain, Theor. Appl. Climatol., 74, 53-67, 2003.

Kasperski, M.: A new wind zone map of Germany, J. Wind Eng., 90, 1271-1287, 2002.

Lamb, H. H.: Historic Storms of the North Sea, British Isles and Northwest Europe, Cambridge Press, 1991.

MacClenahan, P., McKenna, J., Cooper, J. A. G., and O'Kane, B.: Identification of highest magnitude coastal storm events over western Ireland on the basis of wind speed and duration thresholds, Int. J. Clim., 21, 829-842, 2001.

McCallum, E.: The Burns' day storm, 25 January 1990, Weather, 45, 166-173, 1990.

Munich Re: Winterstürme in Europa, Publication of the Munich Re, Ordering Number 2041-E-d, 1993.

Munich Re: Naturkatastrophen in Deutschland: Schadenerfahrungen und Schadenpotentiale, Publication of the Munich Re, Order Number 2798-E-d www.munichre.com, 1999.

Munich Re: Topics, Jahresrückblick Naturkatastrophen 2000, Publication of the Munich Re, Order Number at Munich Re 30202908 (German), 302-02909 (English), 302-02910 (French) or www.munichre.com, 2001.

Munich Re: Winterstorms in Europe (III), Analysis of loss potentials, Order Number at Munich Re: 302-03108 (German), 30203109 (English), 302-03110 (French) or www.munichre.com, 2002.

Palutikof, J. P. and Skellern, A. R.: Storm Severity over Britain, A Report to Commercial Union General Insurance, Climatic Research Unit, School of Environmental Sciences, University of East Anglia, Norwich (UK), 1991.

Schiesser, H. H., Pfister, C., and Bader, J.: Winter storms in Switzerland north of the Alps 1864/1865-1993/1994, Theor. Appl. Climatol., 58, 1-19, 1997.

Swiss Re: Storms over Europe, Losses and Scenarios, Swiss Reinsurance company, Swiss Re publishing, 1993.

Swiss Re: Storm over Europe - An underestimated risk, Swissre Publishing, Order No. 201_00239_en,RN,9,00,3000en or http://www.swissre.com, 2000.

Ulbrich, U., Fink, A. H., Klawa, M., and Pinto, J. G.: Three extreme storms over Europe in December 1999. Weather, 56, 7080,2001 .

Walz, B.: Simulation von Sturmschäden anhand historischer Windfelder im nordwestlichen und zentralen Europa - Ableitung eines Risiko-Indexes, Diploma thesis at the Geographisches Institut der Universität München, 2001.

Wasa group: Changing waves and storms in the northeast Atlantic? Bull. Am. Met. Soc., 79, 741-760, 1998.

Wernli, H., Dirren, S., Liniger, M. A., and Zillig, M.: Dynamical aspects of the life cycle of the winter storm 'Lothar' (24-26 December 1999), Q. J. R. Meteorl. Soc., 128, 405-430, 2002. 